\title{
Role of neuron and non-neuronal cell communication in persistent orofacial pain
}

\author{
Koichi Iwata, Masamichi Shinoda \\ Department of Physiology, Nihon University School of Dentistry, Tokyo, Japan
}

\begin{abstract}
It is well known that trigeminal nerve injury causes hyperexcitability in trigeminal ganglion neurons, which become sensitized. Long after trigeminal nerve damage, trigeminal spinal subnucleus caudalis and upper cervical spinal cord (C1/C2) nociceptive neurons become hyperactive and are sensitized, resulting in persistent orofacial pain. Communication between neurons and non-neuronal cells is believed to be involved in these mechanisms. In this article, the authors highlight several lines of evidence that neuron-glial cell and neuron macrophage communication have essential roles in persistent orofacial pain mechanisms associated with trigeminal nerve injury and/or orofacial inflammation.
\end{abstract}

Keywords: Cell Communication; Orofacial Persistent Pain; Spinal Trigeminal Nucleus; Trigeminal Ganglion.

This is an Open Access article distributed under the terms of the Creative Commons Attribution Non-Commercial License (http://creativecommons.org/licenses/by-nc/4.0/) which permits unrestricted non-commercial use, distribution, and reproduction in any medium, provided the original work is properly cited.

\section{INTRODUCTION}

The oral and craniofacial regions consist of unique structures, including the tongue, teeth, and oral mucosa, which are highly organized for various orofacial functions such as mastication, taste and/or speech. The trigeminal nerve innervates the orofacial structures, and conveys a variety of orofacial sensory information to the central nervous system. In particular, the lingual nerve fibers innervating taste buds in the tongue contribute to taste sensation as well as somatic sensation. The trigeminal nerve consists of 3 branches innervating the orofacial regions somatotopically. Each branch has a different function in orofacial sensation, and their cell soma are located in close proximity to one another. Orofacial noxious, as well as non-noxious, sensory information is sent to the trigeminal spinal subnucleus caudalis $(\mathrm{Vc})$ and upper cervical spinal cord $(\mathrm{C} 1 / \mathrm{C} 2)$ via the trigeminal ganglion (TG) [1]. The Vc has a laminated structure similar to that of the spinal dorsal horn, known as the medullary dorsal horn [2]. Orofacial noxious sensory information is sent to the superficial laminae of the $\mathrm{Vc}$ and $\mathrm{C} 1 / \mathrm{C} 2$. Recent studies have reported that nociceptive neurons in the $\mathrm{Vc}$ and $\mathrm{C} 1 / \mathrm{C} 2$ regions are involved in different functions for processing orofacial nociception [3]. A large number of non-neuronal glial cells, such as satellite glia, microglia, astroglia and oligodendroglia, are distributed throughout the brain. These non-neuronal glial cells are believed to be involved in the nutrition and structural maintenance of neuronal networks in the microenvironment of the peripheral and central nervous system [4]. Conversely, non-neuronal glial cells and macrophages have been reported to have essential roles in the modulation of neuronal excitability, in addition to structural and maintenance functions [5]. After nerve injury or

Received: March 4, 2019 • Revised: April 5, 2019 • Accepted: April 7, 2019

Corresponding Author: Koichi Iwata, Department of Physiology, Nihon University, School of Dentistry, 1-8-13 Kanda-Surugadai, Chiyoda-ku, Tokyo 101-8310, Japan

Tel: +81-3-3219-8112 Fax: +81-3-3219-8341 E-mail: iwata.kouichi@nihon-u.ac.jp

Copyright(c) 2019 Journal of Dental Anesthesia and Pain Medicine 
chronic inflammation in the peripheral structures, non-neuronal glial cells and macrophages are activated and are believed to be involved in the modulation of neuronal excitability [5].

After trigeminal nerve injury, a barrage of action potentials is generated in TG neurons and sent to the $\mathrm{Vc}$ and $\mathrm{C} 1 / \mathrm{C} 2$ regions [6]. After the hyperactivation of $\mathrm{TG}$ neurons, non-neuronal glial cells and macrophages are activated. Activated glial cells and macrophages produce a variety of cytokines that are involved in the modulation of neuronal excitability [7]. It is essential to understand the mechanisms underlying the functional interaction between non-neuronal cells and neurons in the orofacial pathological pain state to develop appropriate treatment strategies for patients with persistent orofacial pain.

\section{SATELLITE GLIA AND NEURON INTERACTION IN THE TG}

It is well known that the soma of a primary afferent neuron is tightly surrounded by satellite glial cells in the TG and dorsal root ganglion (DRG). The gap between the soma of a primary neuron and satellite glial cells is only $20 \mathrm{~nm}$, and is where these cells communicate with one another by releasing chemical messengers knowns as neurotransmitters. Recent studies have indicated that peripheral nerve injury induces morphological changes in satellite glial cells (hypertrophy and enhanced expression glial fibrillary acidic protein) and functional hyperactivity $[8,9]$. In fact, peripheral nerve injury with the blockade of primary neural conduction under local anesthesia does not induce morphological and functional changes in satellite glial cells and attenuates neuropathic pain intensity $[10,11]$. Consequently, although it is certain that the enhancement of primary afferent neuronal activity following peripheral nerve injury or inflammation is involved in morphological and functional changes of satellite glial cells, detailed mechanisms have not been entirely elucidated.

The $\mathrm{P} 2 \mathrm{X} 7$ receptor is a purinergic ionotropic receptor channel expressed in satellite glial cells in the TG [12]. A clinical study reported increased $\mathrm{P} 2 \mathrm{X} 7$ receptor expression in satellite glial cells in the DRG following peripheral nerve injury [13]. Moreover, earlier studies have indicated that nociceptive stimuli elicited adenosine triphosphate (ATP) release from the soma of primary neurons to peripheral tissues, and the sensitivity of satellite glial cells in the TG to ATP was markedly enhanced following orofacial inflammation [12,14]. Enhanced P2X7 signaling in satellite glial cells augments $\mathrm{P} 2 \mathrm{X} 3$ receptor expression in primary TG neurons, which may be a possible mechanism of orofacial mechanical allodynia following peripheral nerve injury [15].

P2X7 signaling in satellite glial cells in the TG also increases intracellular calcium concentration [16]. The increment in intracellular calcium concentration induces the synthesis and release of cytokines such as tumor necrosis factor-alpha (TNF $\alpha$ ) or interleukin (IL) 1-beta (IL-1 $\beta$ ) from satellite glial cells in a sciatic or trigeminal nerve injury model $[17,18]$. IL- $1 \beta$ binds to the IL-1 receptor in small-diameter TG neurons, and IL-1 $\beta$ signaling reduces the outward potassium current responsible for repolarization of the membrane, which enhances TG nociceptive neuronal excitability [19]. Additionally, TNF- $\alpha$ signaling in DRG neurons increases transient receptor potential vanilloid 1 (TRPV1) expression via extracellular signal-regulated kinase (ERK), which enhances TRPV1-dependent inward current [20]. TNF- $\alpha$ signaling also regulates voltage-gated sodium channel (Nav) excitability by the activation of tetrodotoxin (TTX)-sensitive and TTX-resistant Nav 1.3 and Nav 1.8 in DRG neurons via p38 mitogen-activated protein kinase (MAPK) signaling following peripheral nerve injury [21-23]. It is assumed that these mechanisms are also involved in the sensitization of primary nociceptive neurons, which are responsible for orofacial mechanical allodynia following peripheral nerve injury.

\section{MACROPHAGE ACTIVATION IN TG}

Previous studies have indicated that peripheral nerve 
injury induces the increase in the number of resident and proliferating macrophages in the DRG [24-26]. In the TG, trigeminal nerve injury induces extensive macrophage infiltration; these infiltrating macrophages exhibit larger cell bodies and thicker ramifications, which indicate activation [27]. In the DRG, the chemokine C-C motif ligand 2 (CCL2), released from injured neurons, binds to the C-C chemokine receptor type 2 (CCR2) in macrophages, which activates macrophage proliferation in peripheral nerve injury [28,29]. Furthermore, deficiencies in toll-like receptor 2 (TLR2) depresses the enhancement of CCL2 expression in sensory neurons and macrophage infiltration in the sensory ganglion following peripheral nerve injury [30], indicating that the abundant infiltration of activated macrophages in the TG is induced by CCL2 released from injured neurons via TLR2 signaling following trigeminal nerve injury.

Macrophages are also a source of TNF- $\alpha$ in DRG, and $\mathrm{TNF}-\alpha$ is released via intracellular signaling cascades including p38 MAPK and extracellular signal-regulated kinase (ERK) cascades [31-33]. Substance P (SP) expression is enhanced in DRG neurons, and SP release into the DRG after peripheral nerve injury [34]. These reports indicate that SP released from TG neurons binds to the neurokinin 1 receptor, which is expressed in macrophages, resulting in TNF- $\alpha$ release from activated macrophages via the ERK 1/2 and p38 MAPK signaling cascades [35-37]. Based on these reports, TNF- $\alpha$ or SP released from proliferating macrophages, and these signaling pathways may contribute to the enhancement of TG neuronal excitability, resulting in orofacial mechanical allodynia following trigeminal nerve injury [7].

\section{NEURON-GLIAL INTERACTION IN THE Vc AND C1/C2}

Orofacial noxious information is sent to the $\mathrm{Vc}$ and $\mathrm{C} 1 / \mathrm{C} 2$ regions, and nociceptive neurons in these nuclei are somatotopically organized [38]. After trigeminal nerve injury or orofacial inflammation, a barrage of action potentials is generated in TG neurons, which become sensitized [39]. The release of various excitatory neurotransmitters from sensitized primary afferent terminals, such as glutamate, is enhanced, and synaptic transmission is further accelerated in $\mathrm{Vc}$ and $\mathrm{C} 1 / \mathrm{C} 2$ and, subsequently, $\mathrm{Vc}$ and $\mathrm{C} 1 / \mathrm{C} 2$ nociceptive neurons are sensitized.

ERK is phosphorylated in $\mathrm{Vc}$ and $\mathrm{C} 1 / \mathrm{C} 2$ nociceptive neurons approximately $5 \mathrm{~min}$ after noxious stimulation of the orofacial regions [40]. This molecule is known as a useful marker of excitability in nociceptive neurons in the $\mathrm{Vc}$ and $\mathrm{C} 1 / \mathrm{C} 2$ activated by various noxious stimuli to the orofacial regions [38]. ERK phosphorylation is significantly enhanced following trigeminal nerve injury or orofacial inflammation, and this molecule is believed to be involved in the sensitization of $\mathrm{Vc}$ and $\mathrm{C} 1 / \mathrm{C} 2$ nociceptive neurons [41]. It has also been reported that microglia and astroglia are activated in the $\mathrm{Vc}$ and $\mathrm{C} 1 / \mathrm{C} 2$ after trigeminal nerve injury [42,43].

Activated microglial and astroglial cells alter their morphological features and release various molecules that are involved in the modulation of $\mathrm{Vc}$ and $\mathrm{Cl} 1 / \mathrm{C} 2$ nociceptive neuronal activity. The glutamate-glutamine shuttle is one of the possible mechanisms underlying neuron-astroglial cell interaction, which is involved in the enhancement of neuronal activity in $\mathrm{Vc}$ and $\mathrm{C} 1 / \mathrm{C} 2$ neurons following trigeminal nerve injury [44]. After trigeminal nerve injury, astroglial cells are activated and release glutamine. The glutamine is then removed from the primary afferent terminals of the trigeminal nerve, and glutamate release from the terminals is strongly enhanced, resulting in further enhancement of $\mathrm{Vc}$ and $\mathrm{Cl} / \mathrm{C} 2$ nociceptive neuronal activity [42].

Microglial cells are also activated after trigeminal nerve injury [43]. ATP is released from the primary afferent terminals and bind to the $\mathrm{P} 2 \mathrm{X} 4$ receptor in microglial cells, which are then activated. Activated microglial cells are known to release brain-derived neurotrophic factor (BDNF), which binds TrkB in the $\mathrm{Vc}$ and $\mathrm{C} 1 / \mathrm{C} 2$ nociceptive neurons, resulting in hyperexcitation. $\mathrm{KCC} 2$ down-regulation associated with BDNF binding with TrkB is also known to be involved in the enhancement of the $\mathrm{Vc}$ and $\mathrm{C} 1 / \mathrm{C} 2$ nociceptive neuronal activity [45]. 
Recently, it has been reported that microglial cells and astroglial cells closely communicate with one another, and that microglial cells regulate the activation of astroglial cells [46].

After trigeminal nerve injury, a barrage of action potentials is generated and conveyed to TG neurons. Within the TG, various molecules are produced in satellite glial cells and macrophages are activated, and various molecules are generated in these cells and released from these cells, which in turn further enhance TG neuronal activity. According to similar mechanisms, $\mathrm{Vc}$ and $\mathrm{C} 1 / \mathrm{C} 2$ nociceptive neurons are also strongly activated via astrocyte and microglial cell activation. Activated astroglial and microglial cells release various molecules that are involved in the enhancement of $\mathrm{Vc}$ and $\mathrm{C} 1 / \mathrm{C} 2$ neuronal activity. Although these mechanisms are involved in hyperactivation of nociceptive neurons in the $\mathrm{Vc}$ and $\mathrm{C} 1 / \mathrm{C} 2$ regions, resulting in the orofacial persistent pain associated with trigeminal nerve injury.

\section{AUTHOR ORCIDS}

Koichi Iwata: https://orcid.org/0000-0001-5859-9237

Masamichi Shinoda: https://orcid.org/0000-0003-0965-6498

ACKNOWLEDGMENTS: This study was supported in part by research grants from Sato and Uemura Funds from the Nihon University School of Dentistry, a grant from the Dental Research Center in Nihon University School of Dentistry, Nihon University Multidisciplinary Research Grant for (2016 and 2017), and MEXT-Supported Program for the Strategic Research Foundation at Private Universities 2013-2017. The authors declare no competing interests.

\section{REFERENCES}

1. Sessle BJ. The neurobiology of facial and dental pain: present knowledge, future directions. J Dent Res 1987; 66: $962-81$.
2. Dubner R, Bennett GJ. Spinal and trigeminal mechanisms of nociception. Annu Rev Neurosci 1983; 6: 381-418.

3. Bereiter DA, Hirata $\mathrm{H}, \mathrm{Hu}$ JW. Trigeminal subnucleus caudalis: beyond homologies with the spinal dorsal horn. Pain 2000; 88: 221-4.

4. Herculano-Houzel S. The glia/neuron ratio: how it varies uniformly across brain structures and species and what that means for brain physiology and evolution. Glia 2014; 62: $1377-91$

5. Zhang ZJ, Jiang BC, Gao YJ. Chemokines in neuron-glial cell interaction and pathogenesis of neuropathic pain. Cell Mol Life Sci 2017; 74: 3275-91.

6. Tsuboi Y, Takeda M, Tanimoto T, Ikeda M, Matsumoto S, Kitagawa J, et al. Alteration of the second branch of the trigeminal nerve activity following inferior alveolar nerve transection in rats. Pain 2004; 111: 323-34.

7. Batbold D, Shinoda M, Honda K, Furukawa A, Koizumi M, Akasaka R, et al. Macrophages in trigeminal ganglion contribute to ectopic mechanical hypersensitivity following inferior alveolar nerve injury in rats. J Neuroinflammation 2017; 14: 249.

8. Pannese E. The satellite cells of the sensory ganglia. Adv Anat Embryol Cell Biol 1981; 65: 1-111.

9. Li L, Zhou XF. Pericellular Griffonia simplicifolia I isolectin B4-binding ring structures in the dorsal root ganglia following peripheral nerve injury in rats. J Comp Neurol 2001; 439: 259-74.

10. Xie W, Strong JA, Meij JT, Zhang JM, Yu L. Neuropathic pain: early spontaneous afferent activity is the trigger. Pain 2005; 116: 243-56.

11. Xie W, Strong JA, Zhang JM. Early blockade of injured primary sensory afferents reduces glial cell activation in two rat neuropathic pain models. Neuroscience 2009; 160: 847-57.

12. Kushnir R, Cherkas PS, Hanani M. Peripheral inflammation upregulates P2X receptor expression in satellite glial cells of mouse trigeminal ganglia: a calcium imaging study. Neuropharmacology 2011; 61: 739-46.

13. Chessell IP, Hatcher JP, Bountra C, Michel AD, Hughes JP, Green P, et al. Disruption of the P2X7 purinoceptor gene abolishes chronic inflammatory and neuropathic pain. 
Pain 2005; 114: 386-96.

14. Gu Y, Chen Y, Zhang X, Li GW, Wang C, Huang LY. Neuronal soma-satellite glial cell interactions in sensory ganglia and the participation of purinergic receptors. Neuron Glia Biol 2010; 6: 53-62.

15. Chen Y, Zhang X, Wang C, Li G, Gu Y, Huang LY. Activation of $\mathrm{P} 2 \mathrm{X} 7$ receptors in glial satellite cells reduces pain through downregulation of $\mathrm{P} 2 \mathrm{X} 3$ receptors in nociceptive neurons. Proc Natl Acad Sci U S A 2008; 105: $16773-8$.

16. Ceruti S, Fumagalli M, Villa G, Verderio C, Abbracchio MP. Purinoceptor-mediated calcium signaling in primary neuron-glia trigeminal cultures. Cell Calcium 2008; 43: 576-90.

17. Xu JT, Xin WJ, Zang Y, Wu CY, Liu XG. The role of tumor necrosis factor-alpha in the neuropathic pain induced by Lumbar 5 ventral root transection in rat. Pain 2006; 123: 306-21.

18. Takeda M, Tanimoto T, Kadoi J, Nasu M, Takahashi M, Kitagawa J, et al. Enhanced excitability of nociceptive trigeminal ganglion neurons by satellite glial cytokine following peripheral inflammation. Pain 2007; 129: 155-66.

19. Takeda M, Takahashi M, Matsumoto S. Contribution of activated interleukin receptors in trigeminal ganglion neurons to hyperalgesia via satellite glial interleukin-1beta paracrine mechanism. Brain Behav Immun 2008; 22: 101623.

20. Hensellek S, Brell P, Schaible HG, Brauer R, Segond von Banchet G. The cytokine TNFalpha increases the proportion of DRG neurones expressing the TRPV1 receptor via the TNFR1 receptor and ERK activation. Mol Cell Neurosci 2007; 36: 381-91.

21. Chen X, Pang RP, Shen KF, Zimmermann M, Xin WJ, $\mathrm{Li}$ YY, et al. TNF-alpha enhances the currents of voltage gated sodium channels in uninjured dorsal root ganglion neurons following motor nerve injury. Exp Neurol 2011; 227: $279-86$.

22. He XH, Zang Y, Chen X, Pang RP, Xu JT, Zhou X, et al. TNF-alpha contributes to up-regulation of Nav1.3 and Nav1.8 in DRG neurons following motor fiber injury. Pain 2010; 151: 266-79.
23. Jin X, Gereau RWt. Acute p38-mediated modulation of tetrodotoxin-resistant sodium channels in mouse sensory neurons by tumor necrosis factor-alpha. J Neurosci 2006; 26: $246-55$.

24. Donegan M, Kernisant M, Cua C, Jasmin L, Ohara PT. Satellite glial cell proliferation in the trigeminal ganglia after chronic constriction injury of the infraorbital nerve. Glia 2013; 61: 2000-8.

25. Komori T, Morikawa Y, Inada T, Hisaoka T, Senba E. Site-specific subtypes of macrophages recruited after peripheral nerve injury. Neuroreport 2011; 22: 911-7.

26. Lu X, Richardson PM. Responses of macrophages in rat dorsal root ganglia following peripheral nerve injury. J Neurocytol 1993; 22: 334-41.

27. Harvey LD, Yin Y, Attarwala IY, Begum G, Deng J, Yan HQ, et al. Administration of DHA Reduces Endoplasmic Reticulum Stress-Associated Inflammation and Alters Microglial or Macrophage Activation in Traumatic Brain Injury. ASN Neuro 2015; 7.

28. Abbadie C, Lindia JA, Cumiskey AM, Peterson LB, Mudgett JS, Bayne EK, et al. Impaired neuropathic pain responses in mice lacking the chemokine receptor CCR2. Proc Natl Acad Sci U S A 2003; 100: 7947-52.

29. Kwon MJ, Shin HY, Cui Y, Kim H, Thi AH, Choi JY, et al. CCL2 Mediates Neuron-Macrophage Interactions to Drive Proregenerative Macrophage Activation Following Preconditioning Injury. J Neurosci 2015; 35: 15934-47.

30. Kim D, You B, Lim H, Lee SJ. Toll-like receptor 2 contributes to chemokine gene expression and macrophage infiltration in the dorsal root ganglia after peripheral nerve injury. Mol Pain 2011; 7: 74.

31. Raghavendra V, Tanga F, Rutkowski MD, DeLeo JA. Anti-hyperalgesic and morphine-sparing actions of propentofylline following peripheral nerve injury in rats: mechanistic implications of spinal glia and proinflammatory cytokines. Pain 2003; 104: 655-64.

32. Wagner R, Myers RR. Endoneurial injection of TNF-alpha produces neuropathic pain behaviors. Neuroreport 1996; 7: 2897-901.

33. Wang CL, Lu CY, Pi CC, Zhuang YJ, Chu CL, Liu WH, et al. Extracellular polysaccharides produced by Gano- 
derma formosanum stimulate macrophage activation via multiple pattern-recognition receptors. BMC Complement Altern Med 2012; 12: 119.

34. Fu C, Yin Z, Yu D, Yang Z. Substance P and calcitonin gene-related peptide expression in dorsal root ganglia in sciatic nerve injury rats. Neural Regen Res 2013; 8: 3124-30.

35. Sun J, Ramnath RD, Zhi L, Tamizhselvi R, Bhatia M. Substance P enhances NF-kappaB transactivation and chemokine response in murine macrophages via ERK1/2 and p38 MAPK signaling pathways. Am J Physiol Cell Physiol 2008; 294: C1586-96.

36. Matsumoto K, Nakajima T, Sakai H, Kato S, Sagara A, Arakawa $\mathrm{K}$, et al. Increased expression of 5-HT3 and NK 1 receptors in 5-fluorouracil-induced mucositis in mouse jejunum. Dig Dis Sci 2013; 58: 3440-51.

37. Bardelli C, Gunella G, Varsaldi F, Balbo P, Del Boca E, Bernardone IS, et al. Expression of functional NK1 receptors in human alveolar macrophages: superoxide anion production, cytokine release and involvement of NF-kappaB pathway. Br J Pharmacol 2005; 145: 385-96.

38. Noma N, Tsuboi Y, Kondo M, Matsumoto M, Sessle BJ, Kitagawa J, et al. Organization of pERK-immunoreactive cells in trigeminal spinal nucleus caudalis and upper cervical cord following capsaicin injection into oral and craniofacial regions in rats. J Comp Neurol 2008; 507: 1428-40.

39. Iwata K, Imai T, Tsuboi Y, Tashiro A, Ogawa A, Morimoto $\mathrm{T}$, et al. Alteration of medullary dorsal horn neuronal activity following inferior alveolar nerve transection in rats.
J Neurophysiol 2001; 86: 2868-77.

40. Ji RR, Baba H, Brenner GJ, Woolf CJ. Nociceptive-specific activation of ERK in spinal neurons contributes to pain hypersensitivity. Nat Neurosci 1999; 2: 1114-9.

41. Suzuki I, Tsuboi Y, Shinoda M, Shibuta K, Honda K, Katagiri A, et al. Involvement of ERK phosphorylation of trigeminal spinal subnucleus caudalis neurons in thermal hypersensitivity in rats with infraorbital nerve injury. PLoS One 2013; 8: e57278.

42. Okada-Ogawa A, Suzuki I, Sessle BJ, Chiang CY, Salter MW, Dostrovsky JO, et al. Astroglia in medullary dorsal horn (trigeminal spinal subnucleus caudalis) are involved in trigeminal neuropathic pain mechanisms. J Neurosci 2009; 29: 11161-71.

43. Shibuta K, Suzuki I, Shinoda M, Tsuboi Y, Honda K, Shimizu N, et al. Organization of hyperactive microglial cells in trigeminal spinal subnucleus caudalis and upper cervical spinal cord associated with orofacial neuropathic pain. Brain Res 2012; 1451: 74-86.

44. Chiang CY, Dostrovsky JO, Iwata K, Sessle BJ. Role of glia in orofacial pain. Neuroscientist 2011; 17: 303-20.

45. Inoue K. A state-of-the-art perspective on microgliopathic pain. Open Biol 2018; 8.

46. Rothhammer V, Borucki DM, Tjon EC, Takenaka MC, Chao CC, Ardura-Fabregat A, et al. Microglial control of astrocytes in response to microbial metabolites. Nature 2018; 557: 724-8. 